\title{
Factors affecting the choice of type of delivery with breast feeding in Iranian mothers
}

\author{
Farangis Sharifi ${ }^{1}$, Soheila Nouraei ${ }^{2}$, Nader Sharifi $^{3}$
}

\author{
${ }^{1}$ Department of Midwifery, Kazerun Branch, Islamic Azad University, Kazerun, Iran \\ ${ }^{2}$ Department of Midwifery, Shahid Beheshti University of Medical Sciences, Tehran, Iran \\ ${ }^{3}$ Ph.D. Candidate of Health Education \& Promotion, School of Public Health, Tehran University of Medical \\ Sciences, Tehran, Iran
}

\section{Type of article: Original}

\begin{abstract}
Objective: This study assessed the factors affecting the choice of type of delivery with breast feeding in Iranian mothers.

Methods: This Cross section descriptive analytic study was performed using a random sampling technique, using data from 400 pregnant women who attended the maternity centers in Borazjan and Kazerun in Iran in 2014. A questionnaire covering demographic characteristics, mode of delivery and postpartum conditions was completed for each mother. Descriptive analysis and Chi square test were used along with SPSS 23 software to statistically analyze the data and p-value less than 0.05 was considered for statistical significance.

Results: In this study, the rate of normal delivery and cesarean operation are considered equal. In the main factors influencing the choice of delivery, mothers' education level $(\mathrm{p}=0.028)$ and pregnancy status $(\mathrm{p}=0.041)$ showed a significant relationship. Although no significant association between child nutrition with the type of delivery was found, duration of breastfeeding with the type of delivery showed significant association $(\mathrm{p}=0.046)$.

Conclusion: Although cesarean delivery in many cases is life-saving for mother and fetus; in addition to medical indications, parents with higher education and pregnancy status are also important factors in increasing the rate of cesarean section compared to vaginal delivery. Babies of mothers with normal delivery had a longer time of breastfeeding. Further studies in Iran are necessary, regarding the reasons for high cesarean section and their outcomes.
\end{abstract}

Keywords: Breast-feeding, Factor, Iran , Delivery

\section{Introduction}

The cesarean operation is one of the most common abdominal surgeries, and the rate of its mortality and side effects is higher than normal delivery (1). Despite the lack of increase of emergencies in obstetrics and gynecology, the rate of cesarean operations has increased in many parts of the world (2). Indeed it has reached more than $50 \%$ in some countries (3-9), and in Iran, half of the babies born are born by cesarean operation (10). This is despite the fact that, based on World Health Organization statistics, according to the side effects and problems of cesarean operation, it can be acceptable up to a maximum $15 \%$, and only when delivery through the normal channel is not possible, or is accompanied with serious risks for mother and her baby, it is suggested (11). The results of some studies have shown that the main reason of increase of cesarean operation is the demand by the mother's themselves (12). Perhaps some individual factors such as job, education, age, and pregnancy status are important in selecting the type of delivery of pregnant mothers. As conditions after delivery are different in cesarean operation and normal delivery, it will be effective in the nutritional and growth trend of the child, and even in breast feeding. In cesarean operations, there is a serious delay of lactation, the baby is poorer in sucking, the possibility of successful breast feeding is less and at first is delayed, and the breast feeding period is shorter (13).

\section{Corresponding author:}

Farangis Sharifi, Department of Midwifery, Kazerun Branch, Islamic Azad University, Kazerun, Iran. Tel: +98.7142230507, Email: f_sharifi44@yahoo.com

Received: November 10, 2016, Accepted: April 14, 2017, Published: September 2017

iThenticate screening: March 26, 2017, English editing: June 12, 2017, Quality control: July 14, 2017

This article has been reviewed / commented by three experts

(C) 2017 The Authors. This is an open access article under the terms of the Creative Commons Attribution-NonCommercialNoDerivs License, which permits use and distribution in any medium, provided the original work is properly cited, the use is non-commercial and no modifications or adaptations are made. 


\section{Material and Methods}

This cross sectional descriptive analytic study was performed by a two-step simple random sampling technique, after consulting a statistician, taking $10 \%$ probability sample attrition, about $95 \%$ and $0.5 \%$ error using statistical formulas, 400 people were selected, using data from 400 pregnant women who attended health centers in Kazerun and Borazjan in Iran in 2014. First, a list of all maternity centers in Kazerun and Borazjan was prepared and the mean number of deliveries in each health center was noted. Then, five centers with suitable delivery rates were randomly selected and eighty cases were randomly enrolled from each center. We considered gestational pregnant women after childbirth, and established absence of anxiety and depression as inclusion criteria. Cases which failed to fill the questionnaire were excluded. The method of data collection in our study was by reviewing medical record files and filling questionnaires which were completed by trained persons who interviewed the mothers. After identifying the participants and obtaining written consent, a 20 -item questionnaire was developed to review the terms and conditions of delivery, and 2, 6,12, and 12 months after delivery, in-person follow-up on conditions of child and mother such as kind of nutrition, type of delivery, education level, age, living area, weaning time, etc., was carried out. Study conditions were similar in all centers. Data were then entered into a computer and analyzed using IBM( ) SPSS $\odot$ Statistics version 23 (IBM(C) Corp., Armonk, NY, USA) and descriptive analysis and Chi square test were used to statistically analyze the data. P-value less than 0.05 was considered for statistical significance. The study was approved by the medical ethics committee of KAUM according to the Helsinki declaration, and an informed written consent was also given by each participant.

\section{Results}

Table 1 shows distribution of demographic variables and their relationship with the type of delivery. From 400 females who underwent analysis about 55\% (113 people in CS (cesarean section) group and 108 people in NVD (normal vaginal delivery) group) were 26-34 years. In review of mother's job, the highest percentage $(81 \%, 324$ person) were housewives and in total about $62 \%$ (246 person) of mothers had diploma or higher education and the cesarean rate in this group was higher (136 person) than NVD group (110 person). Also, results showed that unwanted pregnancies were much less than wanted ones, and there were a significant relationship in this case, such that normal delivery was more in unwanted pregnancies than cesarean operation $(\mathrm{p}=0.041)$. According to Table 2 , mother's job, education level and age were not related with breast feeding period $(p>0.05)$. According to our findings (Table 3 ), there were no significant relationship between type of delivery and type of child nutrition $(p=0.299)$ but other results showed that there was a significant relationship between type of delivery and the time of discontinuing breast-feeding $(\mathrm{p}=0.046)$.

Table 1. Demographic variables and their relationship with the type of delivery

\begin{tabular}{|c|c|c|c|c|c|}
\hline \multirow{3}{*}{ Variable } & & \multicolumn{3}{|c|}{ Type of delivery } & \multirow[t]{3}{*}{ p-value } \\
\hline & & \multirow{2}{*}{$\begin{array}{l}\text { Total; n (\%) } \\
400(100)\end{array}$} & \multirow{2}{*}{$\begin{array}{l}\text { CS; n (\%) } \\
200(50)\end{array}$} & \multirow{2}{*}{$\begin{array}{l}\text { NVD; n (\%) } \\
200(50)\end{array}$} & \\
\hline & & & & & \\
\hline \multirow[t]{3}{*}{ Mother age (year) } & $<25$ & $101(25.25)$ & $55(27.5)$ & $46(23)$ & \multirow[t]{3}{*}{0.522} \\
\hline & $26-34$ & $221(55.25)$ & $113(56.5)$ & $108(54)$ & \\
\hline & $>35$ & $78(19.5)$ & $32(16)$ & $46(23)$ & \\
\hline \multirow[t]{4}{*}{ Mother's job } & Housewife & $324(81.0)$ & $156(78.0)$ & $168(84.0)$ & \multirow[t]{4}{*}{0.463} \\
\hline & Employee & $58(14.5)$ & $34(17.0)$ & $24(12.0)$ & \\
\hline & Self-employed & $3(0.8)$ & $2(1.0)$ & $1(0.5)$ & \\
\hline & Student & $15(3.8)$ & $8(4.0)$ & $7(3.5)$ & \\
\hline \multirow[t]{5}{*}{ Mother's Education level } & Primary & $7(1.75)$ & $2(1)$ & $5(2.5)$ & \multirow[t]{5}{*}{0.028} \\
\hline & Under Diploma & $147(36.75)$ & $62(31)$ & $85(42.5)$ & \\
\hline & Diploma & $170(42.5)$ & $88(44)$ & $82(41)$ & \\
\hline & Bachelor & $75(18.75)$ & $47(3.5)$ & $28(14)$ & \\
\hline & Master & $1(0.25)$ & $1(0.5)$ & - & \\
\hline \multirow[t]{2}{*}{ Living area } & Town & $397(99.25)$ & $198(99)$ & $199(99.5)$ & \multirow[t]{2}{*}{0.562} \\
\hline & Village & $3(0.75)$ & $2(1)$ & $1(0.5)$ & \\
\hline \multirow[t]{2}{*}{ Pregnancy status } & Unwanted & $46(11.5)$ & $16(8)$ & $30(15)$ & \multirow[t]{2}{*}{0.041} \\
\hline & Wanted & $354(88.5)$ & $184(92)$ & $170(85)$ & \\
\hline
\end{tabular}

n: number, CS: cesarean section, NVD: normal vaginal delivery, $\mathrm{p}<0.05$ (significant) 
Table 2. The relationship between breast feeding period with Mother's job, Education level and age

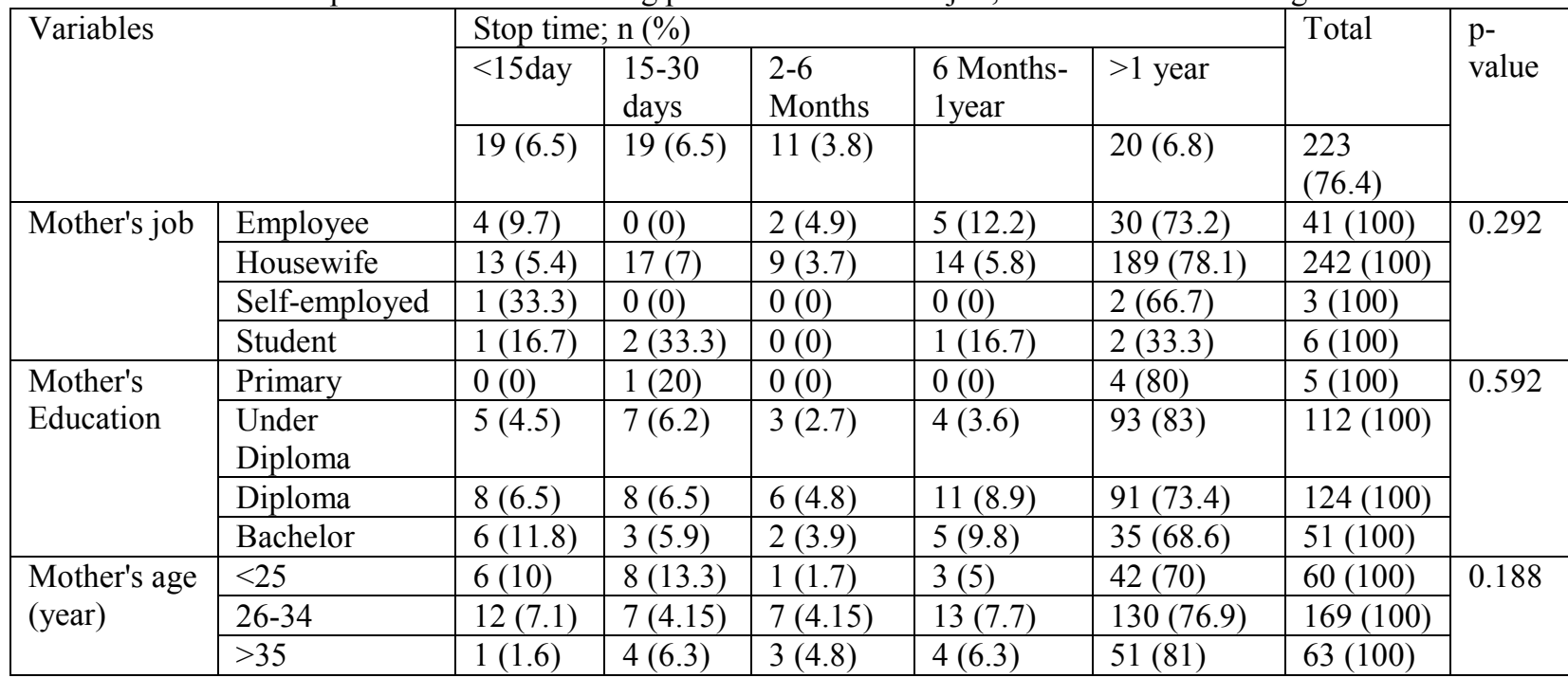

$\mathrm{p}<0.05$ (significant)

Table 3. Kind of nutrition and their relationship with the type of delivery

\begin{tabular}{|c|c|c|c|c|c|}
\hline \multicolumn{2}{|l|}{ Variables } & \multicolumn{3}{|c|}{ Type of delivery } & \multirow[t]{3}{*}{ p-value } \\
\hline & & \multirow{2}{*}{$\begin{array}{l}\text { Total; n (\%) } \\
400(100)\end{array}$} & \multirow{2}{*}{$\begin{array}{l}\text { CS; n (\%) } \\
200(50)\end{array}$} & \multirow{2}{*}{$\begin{array}{l}\text { NVD; n (\%) } \\
200(50)\end{array}$} & \\
\hline & & & & & \\
\hline \multirow[t]{3}{*}{ Kind of nutrition } & Breast Feeding & $334(83.5)$ & $162(81)$ & $172(86)$ & \multirow[t]{3}{*}{0.299} \\
\hline & Milk powder & $39(9.75)$ & $24(12)$ & $15(7.5)$ & \\
\hline & Breast Feeding + Milk powder & $27(6.75)$ & $14(7)$ & $13(6.5)$ & \\
\hline \multirow[t]{6}{*}{ Breastfeeding Duration } & $<15$ days & $19(6.5)$ & $14(9.9)$ & $5(3.3)$ & \multirow[t]{6}{*}{0.046} \\
\hline & 15-30 days & $19(6.5)$ & $10(7)$ & $9(6)$ & \\
\hline & 2-6 months & $11(3.8)$ & $6(4.2)$ & $5(3.3)$ & \\
\hline & 6 months- 1year & $20(6.8)$ & $13(9.2)$ & $7(4.7)$ & \\
\hline & $>1$ year & $223(76.8)$ & $99(69.7)$ & $124(82.7)$ & \\
\hline & Without answer & 108 & 58 & 50 & \\
\hline
\end{tabular}

n: number, CS: cesarean section, NVD: normal vaginal delivery, $\mathrm{p}<0.05$ (significant)

\section{Discussion}

In this study, we have investigated the factors affecting the choice of type of delivery with breast feeding in Iranian mothers. Conducted studies in most other parts of the world, $(5,14,15)$, have shown that the rate of cesarean operation is much higher than World Health Organization statistics, which are usually optional and do not have any medical reason for doing it. In this study, in each of the age groups below 25 and 26-34 years old, cesarean operation had been more common than normal delivery, this is despite the fact that in the age group over 25 , normal delivery was more common, which could be because of the issue that pelvic structure is better developed at this age. Pregnancy status in terms of wanted (intentional) or unwanted (unintentional) pregnancy is also investigated in our study, and shows that unintentional pregnancies were much less than intentional ones, and there is a significant relationship in this case, such that normal delivery was more in unintentional pregnancies than cesarean operation. In this study, the rates of normal delivery and cesarean operation are considered equal and are investigated in effective factors on selecting the type of delivery of pregnant mothers, education, job of mother, place of living, pregnancy status, and following that, relationship of the type of delivery and discontinuation of breast feeding period and child nutrition. In this conducted research, there was a significant relationship between education level of the mother and the type of delivery, such that the rate of cesarean operation is higher among women with higher education in comparison with those with lower education, which in some other similar studies, such as studies conducted by Garmaroodi, et al. (16-19), it is also found that by increasing education level, more mothers prefer cesarean operation. In investigating the effect of the job of mother on selecting the type of delivery in our study, no significant relationship was found, similar to the study of Zamani et al. (19), but research of Garmaroodi, and Ali Mohammadi et al. were significant in this regard $(16,18)$, which no investigation is conducted about this statistical 
difference. Regarding location in terms of living in the city or village, it was also ineffective in selecting the type of delivery in our study, which its reasons could be the issue that most of our patients were urbanist. But in investigating other factors effective on breast feeding period, such as studies of Hajian in Babol (20), and Branger in France (21), there was significant relationship between breast feeding period and job, age and education level of mother. In contrast to those studies, we did not find any significant relationship between those variables and breast feeding period. Similar to the findings of Hwang's study (22), in our study, cesarean sectioned mothers were less successful in breastfeeding duration than those who had normal delivery. Our findings were also consistent with the findings of Throfilofiannakou et al. in Greece (23), Chandrashekher et al. in Western Nepal (24), Batal et al. in Lebanon (25), Mikiel-Kostyra et al. in Poland (26), and Pechlivoni et al. in Athens-Greece (27). Although, in studies conducted by Escamilla in Mexico (28), Lathauwer (29), and Pattle (30), the type of delivery was effective on breastfeeding period, which can be because of better mother outcome after normal delivery vs. cesarean section. Also, in our study, the rate of using milk powder among infants of cesarean sectioned mothers was more than infants of mothers with normal delivery. Thus, type of delivery can be effective in using milk powder, which has different reasons such as insufficient mothers' milk, that was consistent with the studies of Murray (12) and Azaiza (31).

\section{Conclusions}

According to studied research findings, regarding factors affecting the choice of type of delivery with breast feeding, it is necessary to cope with the uncontrolled increase of cesarean operations and achieving a desirable and acceptable level of this type of delivery, knowledge and attitude of women are considered, and it is necessary that they become familiar with the advantages of normal delivery and risks of cesarean operation for mother and infant, and through necessary actions, we can see favorable changes in knowledge and attitudes in this regard.

\section{Acknowledgments:}

We thank the staff and personnel of Kazerun and Borazjan health network who helped us with sampling and procedures during this study.

\section{Conflict of Interest:}

There is no conflict of interest to be declared.

Authors' contributions:

All authors contributed to this project and article equally. All authors read and approved the final manuscript.

\section{References:}

1) Schuitemaker N, Roosmalen J, Dekker G, Dongen P, Geijn H, Gravenhorst JB. Maternal mortality after cesarean section in The Netherlands. Acta Obstet Gynecol Scand. 1997; 76(4): 332-4. doi: 10.1111/j.16000412.1997.tb07987.x. PMID: 9174426.

2) de Muylder X, Thiery M. The cesarean delivery rate can be safely reduced in a developing country. Obstet Gynecol. 1990; 75(3 Pt 1): 360-4. PMID: 2304708.

3) Alimohamadian M, Shariat M, Mahmoudi M, Ramezanzadeh F. Investigation the effect of pregnant women desire on elective cesarean section rate. Payesh. 2003; 2: 133-9.

4) Bailit JL, Love TE, Mercer B. Rising cesarean rates: are patients sicker? Am J Obstet Gynecol. 2004; 191(3): 800-3. doi: 10.1016/j.ajog.2004.01.051. PMID: 15467544.

5) Belizán JM, Showalter E, Castro A, Bastian H, Althabe F, Barros FC, et al. Rates and implications of cesarean sections in Latin America: ecological studyCommentary: all women should have a choiceCommentary: increase in cesarean sections may reflect medical control not women's choice Commentary: "health has become secondary to a sexually attractive body". BMJ. 1999; 319(7222): 1397 402. doi: 10.1136/bmj.319.7222.1397.

6) Gunnervik C, Sydsjö G, Sydsjö A, Selling KE, Josefsson A. Attitudes towards cesarean section in a nationwide sample of obstetricians and gynecologists. Acta Obstet Gynecol Scand. 2008; 87(4): 438-44. doi: 10.1080/00016340802001711. PMID: 18382871.

7) Lee YM, D'Alton ME. Cesarean delivery on maternal request: the impact on mother and newborn. Clin Perinatol. 2008; 35(3): 505-18. doi: 10.1016/j.clp.2008.07.006. PMID: 18952018.

8) Montgomery AA, Emmett CL, Fahey T, Jones C, Ricketts I, Patel RR, et al. Two decision aids for mode of delivery among women with previous cesarean section: randomised controlled trial. BMJ. 2007; 334(7607): 1305. doi: 10.1136/bmj.39217.671019.55. PMID: 17540908, PMCID: PMC1895676.

9) Zhang J, Liu Y, Meikle S, Zheng J, Sun W, Li Z. Cesarean delivery on maternal request in southeast China. Obstet Gynecol. 2008; 111(5): 1077-82. doi: 10.1097/AOG.0b013e31816e349e. PMID: 18448738. 
10) Azami-Aghdash S, Ghojazadeh M, Dehdilani N, Mohammadi M, Asl Amin Abad R. Prevalence and Causes of Cesarean Section in Iran: Systematic Review and Meta-Analysis. Iran J Public Health. 2014; 43(5): 545-55. PMID: 26060756, PMCID: PMC4449402.

11) Cunnigham F, Mocdonald P, Leveno K. Cesarean section and cesarean hysterectomy. Williams obstetrics. 19th texa. Prentice Hail International: INC; 1993.

12) Muula AS. Ethical and Practical Consideration of Women Choosing Cesarean Section Deliveries without "Medical Indication" in Developing Countries. Croat Med J. 2007; 48(1): 94-102. PMID: 17309146, PMCID: PMC2080500.

13) Dewey KG, Nommsen-Rivers LA, Heinig MJ, Cohen RJ. Lactogenesis and infant weight change in the first weeks of life. Adv Exp Med Biol. 2002; 503: 159-66. doi: 10.1007/978-1-4615-0559-4-18. PMID: 12026015.

14) Jackson NV, Irvine LM. The influence of maternal request on the elective cesarean section rate. J Obstet Gynaecol. 1998; 18(2): 115-9. doi: 10.1080/01443619867812. PMID: 15512026.

15) Efekhar K, Steer P. Cesarean section controversy. Women choose cesarean section. BMJ. 2000; 320(7241): 1073. PMID: 10836805.

16) Alimohamadian M, Shariat M, Mahmoodi M, Ramezanzadeh F. The influence of maternal request on the elective cesarean section rate in maternity hospitals in Tehran, Iran. Payesh. 2003; 2(2): 133-9.

17) Fisher J, Smith A, Astbury J. Private health insurance and a healthy personality: new risk factors for obstetric intervention? J Psychosom Obstet Gynaecol. 1995; 16(1): 1-9. doi: 10.3109/01674829509025651. PMID: 7787952.

18) Garmaroodi G. Prevalence of CS and some predisposing factors in primigravida women in maternity delivery units in Tehran in 1999. Maternal and Child Health Publication of Jahad University of Tehran University of Medical Sciences. 2000.

19) Zamani M, Allameh Z, Yadegar N. The relative frequency of the selected delivery method in the pregnant women referring to medical centers of Isfahan in 2002. Iran J Obstet Gynecol Infertil. 2001; 4(7-8): 47-9.

20) Hajian-Tilaki KO. Factors associated with the pattern of breastfeeding in the north of Iran. Ann Hum Biol. 2005; 32(6): 702-13. doi: 10.1080/03014460500272764. PMID: 16418044.

21) Branger B, Cebron M, Picherot G, De Cornulier M. [Factors influencing the duration of breast feeding. A study of 150 women]. Arch Pediatr. 1998; 5(5): 489-96. doi: 10.1016/S0929-693X(99)80312-1. PMID: 9759181.

22) Hwang WJ, Chung WJ, Kang DR, Suh MH. [Factors affecting breastfeeding rate and duration]. J Prev Med Public Health. 2006; 39(1): 74-80. PMID: 16613075.

23) Theofilogiannakou M, Skouroliakou M, Gounaris A, Panagiotakos D, Markantonis SL. Breast-feeding in Athens, Greece: factors associated with its initiation and duration. J Pediatr Gastroenterol Nutr. 2006; 43(3): 379-84. doi: 10.1097/01.mpg.0000228104.97078.bb. PMID: 16954963.

24) Chandrashekhar T, Joshi H, Binu V, Shankar P, Rana M, Ramachandran U. Breast-feeding initiation and determinants of exclusive breast-feeding-a questionnaire survey in an urban population of western Nepal. Public Health Nutr. 2007; 10(02): 192-7. doi: 10.1017/S1368980007248475. PMID: 17261229.

25) Batal M, Boulghourjian C, Abdallah A, Afifi R. Breast-feeding and feeding practices of infants in a developing country: a national survey in Lebanon. Public Health Nutr. 2006; 9(03): 313-9. doi: 10.1079/PHN2006860. PMID: 16684382.

26) Mikiel-Kostyra K, Mazur J, Wojdan-Godek E. Factors affecting exclusive breastfeeding in Poland: crosssectional survey of population-based samples. Soz Praventivmed. 2005; 50(1): 52-9. doi: 10.1007/s00038004-3142-7. PMID: 15771330.

27) Pechlivani F, Vassilakou T, Sarafidou J, Zachou T, Anastasiou CA, Sidossis LS. Prevalence and determinants of exclusive breastfeeding during hospital stay in the area of Athens, Greece. Acta Paediatr. 2005; 94(7): 928-34. doi: 10.1080/08035250410023746. PMID: 16188817.

28) Pérez-Escamilla R, Maulén-Radovan I, Dewey KG. The association between cesarean delivery and breastfeeding outcomes among Mexican women. Am J Public Health. 1996; 86(6): 832-6. doi: 10.2105/AJPH.86.6.832. PMID: 8659658, PMCID: PMC1380403.

29) De Lathouwer S, Lionet C, Lansac J, Body G, Perrotin F. Predictive factors of early cessation of breastfeeding: A prospective study in a university hospital. Eur J Obstet Gynecol Reprod Biol. 2004; 117(2): 169-73. doi: 10.1016/j.ejogrb.2003.10.041. PMID: 15541852.

30) Patel RR, Liebling RE, Murphy DJ. Effect of operative delivery in the second stage of labor on breastfeeding success. Birth. 2003; 30(4): 255-60. doi: 10.1046/j.1523-536X.2003.00255.x. PMID: 14992156.

31) Azaiza F. Patterns of breastfeeding among rural Moslem women in Israel: a descriptive account. Isr J Med Sci. 1995; 31(7): 411-7. PMID: 7607867. 